Revista Brasileira de Meteorologia, v.28, n.4, 357 - 363, 2013

\title{
A SOLUTION OF NONLINEAR EQUATION FOR THE GRAVITY WAVE SPECTRA FROM ADOMIAN DECOMPOSITION METHOD: A FIRST APPROACH
}

\author{
ANTONIO GLEDSON GOULART ${ }^{1}$, DAVIDSON MARTINS MOREIRA ${ }^{2}$, LUIZ CLÁUDIO PIMENTEL ${ }^{3}$ \\ AND JESUS SALVADOR PÉREZ GUERRERO ${ }^{4}$ \\ ${ }^{1}$ Federal University of Pampa, Alegrete, RS, Brazil \\ ${ }^{2}$ Federal University of Southern Border, Chapecó, SC, Brazil \\ ${ }^{3}$ Federal University of Rio de Janeiro, Rio de Janeiro, RJ, Brazil \\ ${ }^{4}$ Brazian Nuclear Energy Commission, Rio de Janeiro, RJ, Brazil \\ agoulart@pq.cnpq.br, davidson@pq.cnpq.br, pimente165@gmail.com,jperez@cnen.gov.br
}

Received December 2012 - Accepted April 2013

\begin{abstract}
In this paper, the equation for the gravity wave spectra in mean atmosphere is analytically solved without linearization by the Adomian decomposition method. As a consequence, the nonlinear nature of problem is preserved and the errors found in the results are only due to the parameterization. The results, with the parameterization applied in the simulations, indicate that the linear solution of the equation is a good approximation only for heights shorter than ten kilometers, because the linearization the equation leads to a solution that does not correctly describe the kinetic energy spectra.
\end{abstract}

Keywords: gravity wave spectra, mean atmosphere, decomposition method.

RESUMO: UMA SOLUÇÃO DA EQUAÇÃO NÃO LINEAR PARA AS ONDAS DE GRAVIDADE A PARTIR DO MÉTODO DA DECOMPOSIÇÃO DE ADOMIAN: UMA PRIMEIRA APROXIMAÇÃO.

Neste artigo, a equação para o espectro de ondas de gravidade na média atmosfera é resolvida analiticamente sem linearização pelo método da decomposição de Adomian. Como consequência, a natureza não-linear do problema é preservada e os erros encontrados nos resultados são devidos somente a parametrização utilizada. Os resultados, com a parametrização usada nas simulações, indicam que a solução linear da equação é uma boa aproximação somente para alturas menores que dez quilômetros, porque a linearização da equação conduz a uma solução que não descreve corretamente o espectro da energia cinética.

Palavras-Chave: espectro de ondas de gravidade, média atmosfera, método da decomposição.

\section{INTRODUCTION}

Atmospheric gravity waves are important in the study of atmospheric circulation, structure and variability. Although there are effects in the lower atmosphere, the major wave influences occur in the middle atmosphere, between 10 and 110 $\mathrm{km}$ altitudes because of the decreasing in air density and the increasing wave amplitudes with altitude (Fritts and Alexander., 2003). Atmospheric gravity waves contribute to the energy and momentum transport and turbulence production (Hodges, 1967; Finnigan and Einaudi, 1981; Finnigan et al., 1984; Fritts and Dunkerton, 1985; Hines, 1988; Finnigan, 1988, 1999; Einaudi and Finnigan, 1993; Nappo, 2002; Zilitinkevich et al., 2009). A more recent work (Tjernstrom et al., 2009, Meillier et al., 2008) suggested that gravity waves are one source of turbulence in Stable Boundary Layer (SBL) and Residual Boundary Layer (RBL). In literature, the general structure for the study of gravity waves is the linear wave theory and, the Taylor-Goldstein equation, is the main governing expression (Gossard and Hooke, 1975; Lindzen and Tung, 1976). The Taylor-Goldstein equation is obtained from the linearization of the primitive set of equations for an inviscid, non-rotating fluid. Chimonas (2002) and Meillier et al. (2008) analyze some properties of gravity waves in the SBL from the Taylor-Goldstein equation. Another 
method of studying the properties of gravity waves is through power spectra. Models of gravity wave spectrum have evolved with time. Various theories constrain gravity wave spectrum to behave in a particular manner over some range of wave numbers or frequencies. These observational and theoretical constraints have led to a canonical gravity wave spectrum that offers insights into mean properties of the gravity wave field and its variations with altitude (Van-Zandt, 1982; Balsley and Carter, 1982; Nakamura et al., 1993; Collins et al., 1994; Smith et al., 1987; Tsuda et al., 1989, 1990; Wilson et al., 1991a, 1991b). It is also important to mention that most pollutants are emitted or chemically produced within the SBL and RBL and its evolution plays an important role in determining pollutant dispersion pathways and the chemical properties of atmospheric pollutants (Salmond and McKendry, 2005).

Gravity waves parameterizations are critical components of virtually all large-scale atmospheric models. Aside from the theoretical deficiencies, even the most powerful available computing architectures still cannot run typical NWP (Numerical Weather Prediction) or climate models fast enough to resolve all relevant scales of atmospheric motion. At present, global models must, in practice, be run with horizontal resolutions that cannot typically resolve atmospheric phenomena shorter than $\sim 10-100 \mathrm{~km}$ or greater for weather prediction and $\sim 100$ $1000 \mathrm{~km}$ or greater for climate prediction. Many atmospheric processes have shorter horizontal scales than these and some of these "subgrid-scale" processes interact with and affect the larger-scale atmosphere in important ways. Since they cannot be resolved, large-scale models must resort to "parameterizations" that capture the salient effects on the resolved atmosphere. Atmospheric gravity waves are one such unresolved.

From the definition of wave momentum flux deposition produced by a harmonic, Medvedev and Klaassen (1995, 2000) obtained an equation for the gravity wave and present a spectral parameterization scheme for calculating gravity wave momentum deposition in the middle atmosphere. The equation obtained is a differential nonlinear equation and it is not solved directly. The height of layer is discretized in sub-intervals in such a manner that inside each interval a linear equation is resolved considering average values of the quantities. This procedure reproduces the solution of the problem. However, it is a very laborious method and is necessary to solve many equations in according with the number of sub-intervals.

Analytical solutions of equations are of fundamental importance in describing and understanding a phenomenon, since all the parameters are expressed in a mathematically closed form and the influence of individual parameters can be easily examined (Moreira et al., 2006, 2009, 2010; Goulart et al., 2008). By analytical we mean that no approximation is done along the solution derivation, except for the series truncation.
They are useful for a variety of applications, such as: providing initial or approximate analyses of alternative pollution scenarios, conducting sensitivity analyses to investigate the effects of various parameters or processes involved in contaminant transport, extrapolation over large times and distances where numerical solutions may be impractical, serving as screening models or benchmark solutions for more complex transport processes that cannot be solved exactly, and for validating more comprehensive numerical solutions of the governing transport equations (Pérez Guerrero et al., 2012).

In this work, we propose an analytical solution for the gravity wave equation. This equation is solved directly without linearization by the Adomian decomposition method (Adomian, 1990, 1994a, 1994b). So, the nonlinear nature of the problem is preserved. Therefore, the errors found are only due to the parameterization used. We consider a first approach in solving the equation taking into account only the variation of the wave spectrum of gravity with time, because the variation of the wave amplitude due to air density with height was discarded. The results are compared with the continuous linear solution. In fact, by solving this equation by the decomposition method, we came out with an analytical formulation for the wave equation. Taking into account the analytical feature and fast numerical convergence of the solution, besides the fact that this sort of solution is not found in the literature for this problem, we are confident to affirm that the proposed solution is a promising technique to handle realistic physical problems. To reach the objective, the paper is organized as follows: we start in section 2 by explaining the decomposition method. Section 3 we introduce the nonlinear solution of the problem. Section 4 we shows the results and discussions. Then, in Section 5, we draw conclusions.

\section{THE ADOMIAN'S DECOMPOSITION METHOD}

The Adomian's decomposition method (Adomian, $1990,1994 a, 1994 b)$ is a new and powerful method for solving nonlinear equations of various kinds. In recent years, the Adomian's decomposition method has been successfully applied to solve many nonlinear equations in applied sciences. (For example, see Babolian and Biazar, 2002; Goulart, et al, 2008; Basak et al., 2009; Azreg-Ainou, 2010). The decomposition method calculates the solutions of nonlinear equations as infinite series in which each term can be easily determined. Each term of these series is a generalized polynomial called Adomian's polynomial.

Considering the following nonlinear differential equation,

$$
\mathbf{L} u+\mathbf{R} u+\mathbf{N} u=g
$$


where $\mathbf{L}$ is the highest-ordered derivative, $\mathbf{R}$ is the remainder of the linear operator, $\mathbf{N} u$ is the nonlinear term and $g$ the term is known.

Isolating the highest-ordered operator $\mathbf{L}$ and applying the inverse operator $\mathbf{L}^{-1}$ in Equation 1 we get,

$$
\mathbf{L}^{-1} \mathbf{L} u=-\mathbf{L}^{-1} \mathbf{R} u-\mathbf{L}^{-1} \mathbf{N} u+\mathbf{L}^{-1} g
$$

For initial-value problems, we conveniently define $\mathbf{L}^{\mathbf{- 1}}$ for $\mathbf{L}=d^{n} / d t^{n}$ as the $\mathrm{n}$-fold definite integration operator from 0 to $t$. For the operator $\mathbf{L}=d / d t$, for example, we have $\mathbf{L}^{-1} \mathbf{L} u=$ $u-u(0)$ and therefore Equation 2 becomes,

$$
u=u(0)-\mathbf{L}^{-1} \mathbf{R} u-\mathbf{L}^{-1} \mathbf{N} u+\mathbf{L}^{-1} g
$$

The Adomian's method decomposes the linear term into an infinite sum of components,

$$
u=\sum_{n=0}^{M} u_{n}
$$

and the nonlinear term may be identified by the decomposition series,

$$
\mathbf{N} u=\sum_{n=0}^{\infty} A_{n}\left(u_{0}, u_{1}, \ldots u_{n}\right)
$$

where the Adomian polynomials $A_{n}$ are obtained from an expansion in Taylor series of the term nonlinear around the first term of series $u_{0}$.

In this paper we use the first three Adomian polynomials described bellow, where $f\left(u_{0}\right)=\mathbf{N}\left(u_{0}\right)$ :

$$
\begin{aligned}
& A_{0}=f\left(u_{0}\right) \\
& A_{1}=u_{1} f^{\prime}\left(u_{0}\right) \\
& A_{2}=u_{2} f^{\prime}\left(u_{0}\right)+\frac{1}{2} u_{1}^{2} f^{\prime \prime}\left(u_{0}\right) \\
& A_{3}=u_{3} f^{\prime}\left(u_{0}\right)+u_{1} u_{2} f^{\prime \prime}\left(u_{0}\right)+\frac{1}{6} u_{1}^{3} f^{\prime \prime \prime}\left(u_{0}\right)
\end{aligned}
$$

We remark that the $A_{n}$ are formally obtained from the relation (Adomian, 1994b),

$$
A_{n}=\frac{1}{n !} \frac{d^{n}}{d \lambda^{n}}\left[\mathbf{N}\left(\sum_{i=0}^{\infty} \lambda^{i} u_{i}\right)\right]_{\lambda=0} n=0,1,2, \ldots
$$

\section{THE NONLINEAR EQUATION FOR THE GRAVITY WAVE SPECTRA}

An equation for the evolution of gravity wave spectra with height $z$ was deduced by Medvedev and Klaassen (1995, 2000) from of the momentum flux divergence,

$$
\frac{\partial S\left(m_{R}, z\right)}{\partial z}-\left(-\frac{\rho_{0 z}}{\rho_{0}}+\frac{m_{R z}}{m_{R}}-\beta\left(m_{R}, z\right)\right) S\left(m_{R}, z\right)=0
$$

where $S$ is the power-spectral density of horizontal wind associated with gravity waves at height $Z, \rho_{0}$ is the mean density of air in reference height, $\rho_{0 z}$ is the density of air in height $Z, m_{R}$ is the real part of vertical wavenumber ( $m=m_{R}$ $\left.+i m_{I}\right), m_{R Z}$ is the wavenumber associated with the maximum of gravity wave spectra and $\beta$ is the coefficient of nonlinear damping due to interactions of the component $m_{R}$ with other waves in the spectrum.

To solve the Equation 11 is necessary parameterize the coefficient $\beta$, because it is function of power-spectral density $S$. A parameterization for the coefficient $\beta$ was suggested by Medvedev and Klaassen (1995, 2000),

$$
\beta\left(m_{R}, z\right)=\frac{\sqrt{2 \pi} N(z)}{\sigma_{u}(z)} \exp \left(-\frac{N^{2}(z)}{2 m_{R} \sigma_{u}^{2}(z)}\right)
$$

where $N$ is the Brunt-Väisälä frequency and

$$
\sigma_{u}^{2}(z)=\int_{m_{R}}^{\infty} S\left(m_{R}^{\prime}, z\right) d m_{R}^{\prime}
$$

is the horizontal wind variance created by all waves in the spectrum with vertical wavenumbers larger than the given $m_{R}$.

Substituting Equations 12 and 13 in Equation 11 is obtained,

$$
\begin{aligned}
& \frac{\partial S\left(m_{R}, z\right)}{\partial z}+\left(\frac{\rho_{0 z}}{\rho_{0}}-\frac{m_{R z}}{m_{R}}\right) S\left(m_{R}, z\right)+.2 N(z) \\
& \frac{\sqrt{2 \pi} N(z)}{\sqrt{\int_{m_{R}}^{\infty} S\left(m_{R}, z\right) d m_{R}}} \exp \left(-\frac{N^{2}(z)}{2 m_{R} \int_{m_{R}}^{\infty} S\left(m_{R}, z\right) d m_{R}}\right), \\
& S\left(m_{R}, z\right)=0
\end{aligned}
$$

The evolution of gravity wave spectra with height is given by Equation 14. It is a nonlinear integro-differential equation that has not a simple analytical solution.

\section{ANALYTICAL SOLUTION VIA ADOMIAN'S DECOMPOSITION METHOD}

To solve the Equation 14 is considered the Adomian's decomposition method (Adomian, 1990, 1994a, 1994b) described in section 2. Comparing Equation 11 with Equation 14 identified,

$$
\begin{aligned}
& S\left(m_{R}, z\right) \rightarrow u \\
& \frac{\partial}{\partial z} \rightarrow \mathbf{L}
\end{aligned}
$$




$$
\begin{aligned}
& \left(\frac{\rho_{0 z}}{\rho_{0}}-\frac{m_{R z}}{m_{R}}\right) \rightarrow \mathbf{R} \\
& \frac{\sqrt{2 \pi} N(z)}{\sqrt{\int_{m_{R}}^{\infty} S\left(m_{R}, z\right) d m_{R}}} \exp \left(-\frac{N^{2}(z)}{2 m_{R} \int_{m_{R}}^{\infty} S\left(m_{R}, z\right) d m_{R}}\right) \rightarrow \mathbf{N} \\
& g=0
\end{aligned}
$$

The Equation 4 can be written as follows,

$$
\mathbf{L} u+\mathbf{R} u+\mathbf{N} u=0
$$

The solution of Equation 14 is given by Equation 3 (in this case $\mathbf{L}^{-1} \rightarrow \int d t$ ),

$$
u(t)=u(0)-\mathbf{L}^{-1} \mathbf{R} u-\mathbf{L}^{-1} \mathbf{N} u
$$

Now, we apply the decomposition method in Equation 21. Substituting Equations 4 and 5 in Expression 21 we can identify,

$$
\begin{aligned}
& u_{0}=u(0) \\
& u_{1}=-\left(\mathbf{R} \mathbf{L}^{-1} u_{0}+\mathbf{L}^{-1} \mathrm{~A}_{0}\right) \\
& u_{2}=-\left(\mathbf{R} \mathbf{L}^{-1} u_{1}+\mathbf{L}^{-1} \mathrm{~A}_{1}\right) \\
& u_{n}=-\left(\mathbf{R} \mathbf{L}^{-1} u_{n-1}+\mathbf{L}^{-1} \mathrm{~A}_{\mathrm{n}-1}\right)
\end{aligned}
$$

where $A_{n}$ are the Adomian's polynomials calculated from Equation 10. Then, the solution of Equation 14 is,

$$
S\left(m_{R}, z\right)=\sum_{n=0}^{n=8} u_{n}
$$

where $u_{n}$ calculated from Equation 25. For the summation in Equation 26, three terms were necessary for a good convergence (considering an error in the second decimal place).

\section{RESULTS AND DISCUSSION}

As discussed in the introduction, in this work, we propose an analytical solution for the gravity wave equation. Now, we compare the solution obtained in this work (Equation 26), which considers the nonlinearity of the equation, with the linear solution obtained when it considers the average values of horizontal wind variance $\int_{m_{R}}^{\infty} S\left(m_{R}, z\right) d m_{R}$ appearing in Equation 14. The terms $u_{n}$ are calculated from Equation 25.

The solution of Equation 14 requires the value of gravity wave spectra in a reference height. We assume that the gravity wave spectra consists of a general Desaubies spectrum form (Desaubies, 1976) in $Z=0\left(S\left(m_{R}, 0\right)=S_{0}\right)$,

$$
S_{0}=a_{0} \frac{N^{2}}{m_{*}^{3}} \frac{m_{R} / m_{*}}{1+\left(m_{R} / m_{*}\right)^{4}}
$$

where $a_{0}$ is a constant, $m_{*}$ is the wavenumber associated with the maximum of gravity wave spectra, $N$ is Brunt-Väisälä frequency. For comparison of gravity wave spectra calculated from expression 26 with the linear solution of Equation 14 we consider the values used by Medvedev and Klaassen (2000) for $a_{0}, m_{*}$ and $N$, namely $a_{0}=1 / 6, m_{*}=0.006 m^{-1}$ and $N=0.02 \mathrm{~s}^{-1}$. In Equation 17 is considered $m_{R Z} / m_{R}=m_{R} / \sqrt{R_{i}}$, where $R_{i}$ is Richardson flux number. In this case $R_{i}=1$. Considering the initial spectra given by Equation 19 it is possible to calculate analytically the integrals of Equation 26,

$$
\begin{gathered}
\int_{m_{R}}^{\infty} a_{0} \frac{N^{2}}{m_{*}^{3}} \frac{m_{R} / m_{*}}{1+\left(m_{R} / m_{*}\right)^{4}} d m_{R}=a \\
a_{0} \frac{N^{2}}{2 m_{*}^{2}} \arctan \left(\frac{m_{*}^{2}}{m_{R}^{2}}\right) \text { for } m_{R}>0
\end{gathered}
$$

Substituting Equation 28 in Equation 26, we obtain a simple algebraic expression that, although long, requires a time machine extremely small. Figure 1 shows the good agreement between the solution of Equation 14 by the Adomian method (Equation 26) and the numerical Implicit Runge-Kutta method (step size 0.005).

Figures 2 to 4 show the gravity wave spectra calculated from Equation 26 (solid line) and calculated from linear solution of Equation 14 (dotted line). The Figures. 2 and 3 indicate that the linear solution of Equation 14 is a good approximation for small height $(<10 \mathrm{~km})$. However, the Figure 4 show that the linear solution is not a good approximation of solution of Equation 14 for height $>10 \mathrm{~km}$.

The Equation 14 is nonlinear due to the parameterization of coefficient $\beta$ expressed in Equation 8. It is the coefficient of nonlinear damping due to interactions of the component $m_{R}$ with other waves in the spectrum. This term is essentially nonlinear. Its linearization leads to a completely incorrect solution in height above of the $10 \mathrm{~km}$. Therefore, the linear solution cannot be used to correctly describe the spectrum of kinetic energy when considering height above $10 \mathrm{~km}$ (Figure 3 ).

\section{CONCLUSIONS}

In this study, the nonlinear equation of the evolution of gravity wave spectra with height $z$ was analytically solved without linearization by the decomposition method, so the nonlinear nature of problem was preserved. Therefore, mathematically, the errors found are only due to the parameterization used. As a test, we used a spectral parameterization scheme for calculating gravity wave momentum deposition in the middle atmosphere from Equation 14 solved by the method of decomposition and compared with a linear solution. The linear solution is obtained when considering the constant value for the beta 


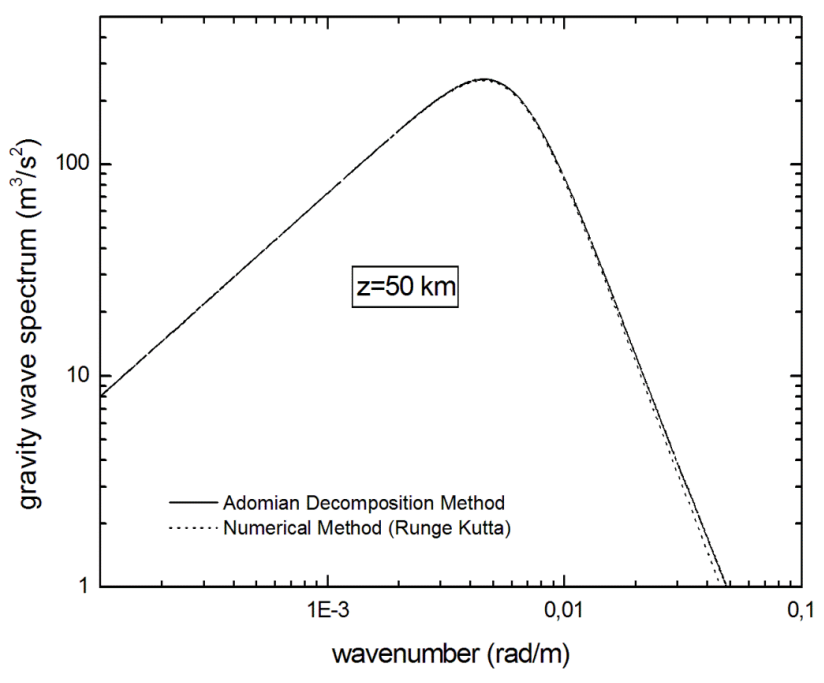

Figure 1 - Gravity wave spectra calculated from Equation 26 (solid line) and with numerical RungeKutta (dotted line) for the height $\mathrm{z}=$ $50 \mathrm{~km}$.

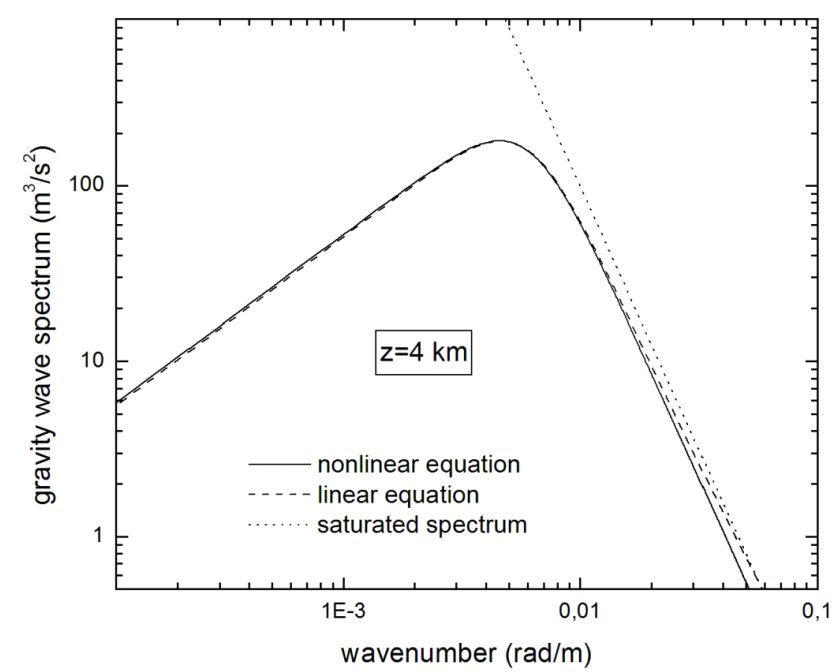

Figure 2 - Gravity wave spectra calculated from Equation 26 (solid line) and with linear solution of Equation 11 (dashed line) for the height $\mathrm{z}=4 \mathrm{~km}$. The dotted line represents the saturated limit.

coefficient in Equation 14. This proposed parameterization involves nonlinear wave interactions. Our results indicate that the linear solution of the resultant equation is a good approximation of the solution only for small height $(<10$ $\mathrm{km})$. However, the linear solution is not a good approximation of the solution of the resultant equation for height $>10 \mathrm{~km}$, because the linearization of the beta coefficient leads to a solution that does not correctly describe the kinetic energy spectra. The discrepancies depend not on the solution of the nonlinear equation, but on the equation itself, which it is only a reality model. In the model proposed by Medvedev and Klaassen $(1995,2000)$ the layer height was discretized

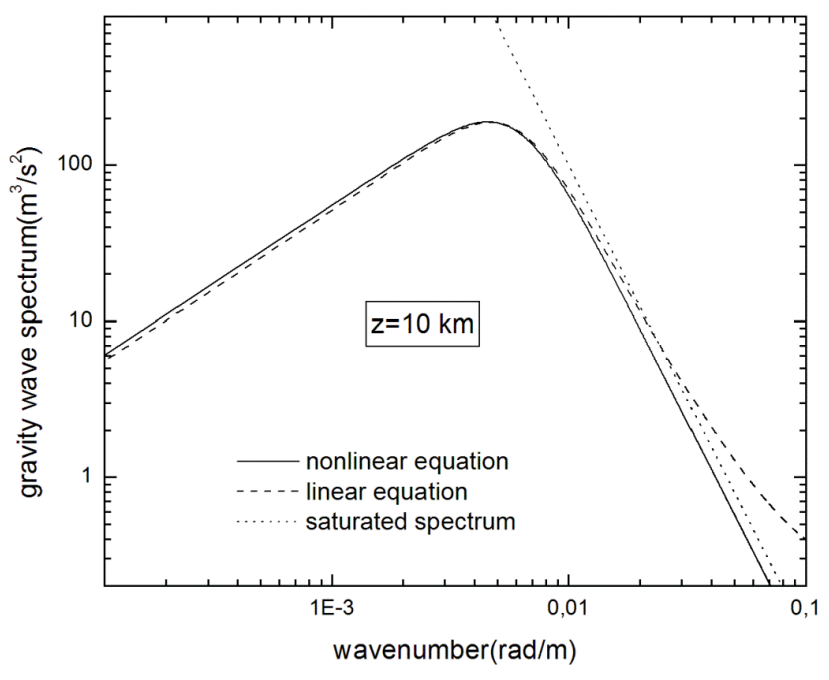

Figure 3 - Gravity wave spectra calculated from Equation 26 (solid line) and with linear solution of Equation 11 (dashed line) for the height $\mathrm{z}=10 \mathrm{~km}$. The dotted line represents the saturated limit.

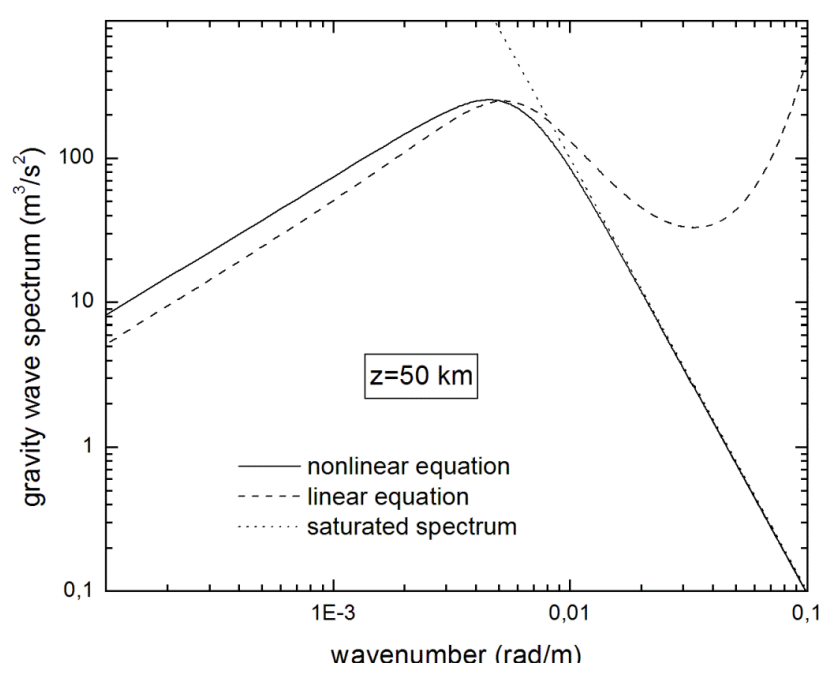

Figure 4 - Gravity wave spectra calculated from Equation 26 (solid line) and with linear solution of Equation 11 (dashed line) for the height $\mathrm{z}=50 \mathrm{~km}$. The dotted line represents the saturated limit, .

in sub-intervals of $500 \mathrm{~m}$, in such a manner that inside each interval a linear equation is resolved considering average value of the quantities. This procedure accurately reproduces the problem solution, because the distance of $500 \mathrm{~m}$ is much smaller than the maximum distance at which the linear solution can be employed. However it is a very laborious method, it is necessary to solve many equations as are the number of subintervals. This is an approximation used when you cannot solve the resulting equations from the parameterization employed. In this work, the equation for the gravity wave spectra in mean atmosphere was analytically solved without linearization by the decomposition method. 
Taking into account the analytical feature and fast numerical convergence of the solution, besides the fact that this sort of solution is not found in the literature for this problem, we are confident to affirm that the proposed solution is a promising technique to handle realistic physical problems. In view of the potential usefulness of the decomposition method it would be desirable to extend the applicability of the method to test other parameterizations. Work in this direction is in progress.

\section{ACKNOWLEDGMENTS}

The authors thank to CNPq for the financial support of this work

\section{REFERENCES}

ADOMIAN, G. A review of the decomposition method and some recent results for nonlinear equations. Mathematical and Computer Modelling, v. 13, n. 7, p. 17-43, 1990.

ADOMIAN, G.. Solution of physical problems by decomposition. Computers and Mathematics with Applications, v. 27, n. 9-10, p. 145-154, 1994a.

ADOMIAN, G. Solving frontier problems of physics: the decomposition method. Boston: Kluwer Academic Publishers, 1994b. 354 p.

AZREG-AINOU, M. Developed Adomian method for quadratic Kaluza-Klein relativity. Classical and quantum gravity, v. 27, n. 1, p. 015012, 2010.

BABOLIAN, E., BIAZAR, J. Solving the problem of biological species living together by Adomian decomposition method. Applied Mathematics and Computation, v. 129, p. 339-343, 2002.

BALSLEY, B.B., CARTER, D.A. The spectrum of atmospheric velocity fluctuations at 8 and $86 \mathrm{~km}$. Geophysical Research Letters. v. 9, p. 465-468, 1982.

BASAK, K.C., RAY, P.C., BERA, R.K. Solution of non-linear Klein-Gordon Eq. with a quadratic non-linear term by Adomian decomposition method. Communications in Nonlinear Science and Numerical Simulation, v. 14, n. 3, p. 718-723, 2009.

CHIMONAS, G. On internal gravity waves associated with the stable boundary layer. Boundary-Layer Meteorology, v. 102, p. 139-155, 2002.

COLLINS, R.L., NOMURA, A., GARDNER, C. Gravity waves in the upper mesosphere over Antarctica: Lidar observations at the South Pole and Syowa. Journal of Geophysical Research, v. 99, p. 5475-5485, 1994.

DESAUBIES, Y. Analytical representation of internal wave spectra. Journal of Physical Oceanography, v. 6, p. 976-981, 1976.
EFINAUDI, F., FINNIGAN, J.J. Wave-turbulence dynamics in the stably stratified boundary layer. Journal of the Atmospheric Sciences, v. 50, p. 1841-1864, 1993.

FINNIGAN, J.J. Kinetic energy transfer between internal gravity waves and turbulence. Journal of the Atmospheric Sciences, v. 45, p. 486-505, 1988.

FINNIGAN, J.J. A note on wave-turbulence interaction and the possibility of scaling the very stable boundary layer. Boundary-Layer Meteorology, v. 90, p. 529-539, 1999.

FINNIGAN, J.J., EINAUDI, F. The interaction between an internal gravity wave and the planetary boundary layer. Part II: effect of the wave on the turbulence structure. Quarterly Journal of the Royal Meteorological Society, v. 107, p. 807-832, 1981.

FRITTS, D.C., ALEXANDER, M.J. Gravity wave dynamics and effects in the middle atmosphere. Reviews of Geophysics, v. 41, n. 1, p. 1003, 2003.

FRITTS, D.C., DUNKERTON, T.J. Fluxes of heat and constituents due to convectively unstable gravity waves. Journal of the Atmospheric Sciences, v. 42, p. 549-556, 1985.

GOSSARD, E., HOOKE, W. Waves in the Atmosphere, Elsevier Science, New York, 1975, 456 p.

GOULART, A., VILHENA, M. T., BODMANN, B., MOREIRA, D. An analytical solution for the nonlinear energy spectrum by the decomposition method. Journal of Physics A: Mathematical and Theoretical, v. 41, p. 425205, 2008.

HINES, C.O. A modeling of atmospheric gravity waves and wave drag generated by isotropic and anisotropic terrain. Journal of the Atmospheric Sciences, v. 45, p. 309-322, 1988.

HODGES, R.R. Generation of turbulence in the upper atmosphere by internal gravity waves. Journal of Geophysical Research v. 72, p. 3455-3458, 1967.

LINDZEN, R., TUNG, K. Banded convective activity and ducted gravity waves. Monthly Weather Review, v. 104, p. 1602-1617, 1976.

MEDVEDEV, A., KLASSEN, G. Vertical evolution of gravity wave spectra and the parameterization of associated wave drag. Journal of Geophysical Research, v. 100, p. 25841 25853, 1995.

MEDVEDEV, A., KLASSEN, G. Parameterization of gravity wave momentum deposition based on nonlinear wave interactions: basic formulation and sensitivity tests. Journal Atmospheric and Solar-Terrestrial Physics, v. 62, p. 1015-1033, 2000.

MEILLIER, R., FREHLICH, J., BASLEY, B. Modulation of small-scales turbulence by ducted gravity waves in the nocturnal boundary layer. Journal of the Atmospheric Sciences, v. 65, p. 1414-1427, 2008. 
MOREIRA, D.M., TIRABASSI, T., VILHENA, M.T., GOULART, A.G. A multi-layer model for pollutant dispersion with dry deposition to the ground. Atmospheric Environment, p. 1859-1865, 2010.

MOREIRA, D.M., VILHENA, M.T., BUSKE, D. ,TIRABASSI, T. The GILTT solution of the advection-diffusion equation for an inhomogeneous and nonstationary PBL. Atmospheric Environment, v. 40, n. 17, p. 3186-3194, 2006.

MORIEIRA, D.M., VILHENA, M.T., BUSKE, D., TIRABASSI, T. The state-of-art of the GILTT method to simulate pollutant dispersion in the atmosphere. Atmospheric Research, v. 92, p. 1-17, 2009.

NAKAMURA, T., TSUDA, T., FUKAO, S., KATO, S., MANSON, A., MEEK, C. Comparative observations of short-period gravity waves (10-100 $\mathrm{min})$ in the mesosphere in 1989 by Saskatoon MF radar (52 N), Canada and the MU radar (35_N), Radio Science, v. 28, p. 729-746, 1993.

NAPPO, C.J. An introduction to atmospheric gravity waves. Academic Press, London, 2002, 276 p.

PÉREZ GUERRERO, J.S., PIMENTEL, L.C.G., OLIVEIRAJÚNUIOR, J.F., HEILBRON FILHO, P.F.L., ULKE, A.G., A unified analytical solution of the steady-state atmospheric diffusion equation. Atmospheric Environment, v. 55, p. 201-212, 2012.

SALMOND, J.A., MCKENDRY, I.G. A review of turbulence in the very stable nocturnal boundary layer and its implications for air quality. Progress in Physical Geography, v. 29, n. 2, p. 171-188, 2005.

SMITH, S.A., FRITTS, D.C., VANZANDT, T.E. Evidence for a saturated spectrum of atmospheric gravity waves. Journal of the Atmospheric Sciences, v. 44, p. 1404-1410, 1987.
TJERNSTROM, M., BASLEY, B., SVENSSON, G., NAPPO, C. The effects of critical layers on Residual Layer Turbulence. Journal of the Atmospheric Sciences, v. 66, p. 468-480, 2009.

TSUDA, T., INOUE, T., FRITTS, D.C., VANZANDT, T.E., KATO, S., SATO, T., FKAO, S. MST radar observations of a saturated gravity wave spectrum. Journal of the Atmospheric Sciences, v. 46, p. 2440-2447, 1989.

TSUDA, T., KATO, S., YOKOI, T., INOUE, T., YAMAMOTO, M., VANZANDT, T.E., FUKAO, S., SATO, T. Gravity waves in the mesosphere observed with the middle and upper atmosphere radar. Radio Science, v. 25, p. 1005-1018, 1990.

VANZANDT, T.E. A universal spectrum of buoyancy waves in the atmosphere, Geophysical Research Letters, v. 9, p. 575-578, 1982.

WILSON, R., CHANIN, M.. HAUCHECORNE, A. Gravity waves in the middle atmosphere observed by Rayleigh lidar, 1, Case studies. Journal of Geophysical Research, v. 96, p. 5153-5167, 1991a.

WILSON, R., CHANIN, M., HAUCHECORNE, A. Gravity waves in the middle atmosphere observed by Rayleigh lidar, part 2, Climatology. Journal of Geophysical Research, v. 96, p. 5169-5183, $1991 b$.

ZILINTIKEVICH, S.S., ELPERIN, T., KLEEORIN, N., L'VOV, V., ROGACHEVSKII, I. Energy- and Flux-Budget Turbulence Closure Model for Stably Stratified Flows. Part II: The Role of Internal Gravity Waves. Boundary-Layer Meteorology, v. 133, p. 139-164, 2009. 